JOURNAL OF LATIN AMERICAN SCIENCES AND CULTURE

Vol. 1 - 2019

Universidad Privada del Valle - Bolivia

https://doi.org/10.52428/2788891v1i1.39

\title{
Conexión entre Industria y Academia
}

\author{
Roberto Guachi,
}

Director of International Exchange and Cooperation | Ecuador

Andean Road Countries for Science and Technology

Los descubrimientos en ciencias básicas que lideran el desarrollo de aplicaciones prácticas en la industria han sido, en su mayoría, desarrollados en la Academia.

El principal obstáculo para la investigación en la mayoría de las instituciones Latinoamericanas es la obtención de financiamiento (Medeiros, \& Trebat, 2017). Investigadores gastan tiempo en busca de colaboraciones o ayudas económicas que puedan cubrir parte de sus proyectos. Es así como la colaboración entre industria y academia juega un papel preponderante para el desarrollo de investigación, la academia contribuye con la experiencia y el conocimiento en ciencia; mientras la industria contribuye con financiamiento y conocimiento del mercado para la aplicación real y eficiente de los estudios desarrollados por academia. La conexión Industria-Academia brinda beneficios compartidos al efectuarse en un marco de legalidad, responsabilidad y propiedad intelectual claramente definidos (Sutz, 2000). El entendimiento de las necesidades y objetivos de las dos partes, Academia e Industria, fortalecen los acuerdos de cooperación, promoviendo una relación sostenible y efectiva. El reconocimiento de las contribuciones de las dos partes, en el desarrollo de los proyectos beneficia el trabajo en equipo.

La identificación de las ventajas de esta cooperación en países desarrollados ha llevado a que el número de acuerdos entre Universidades y Compañías incremente drásticamente en la última década. En Estados Unidos, gigantes empresariales como Amazon o Facebook buscan en esta cooperación el acceso a científicos reconocidos. Estas empresas buscan establecer relaciones duraderas que aceleren la transición de investigación, teórica y diseño a nuevos productos que contribuyan al crecimiento de la economía. Industrias que financian estudiantes de doctorado y post doctorado son muestra de políticas que entienden la importancia de la investigación en el sector productivo.

Los problemas de industrialización, productividad, innovación y desarrollo que comparten gran parte de la industria Latinoamericana pueden atenuarse con la aplicación correcta de programas de cooperación Industria-Academia (Antolín, 1998). Buscar los mecanismos correctos para la aplicación de acuerdos es esencial. La industria Latinoamérica necesita observar en la Academia un camino hacia su fortalecimiento. Sectores estratégicos como producción industrial, salud, telecomunicaciones y movilidad pueden ser beneficiados de acuerdos de cooperación. 
JOURNAL OF LATIN AMERICAN SCIENCES AND CULTURE

Vol. 1 - 2019

Universidad Privada del Valle - Bolivia

https://doi.org/10.52428/2788891v1i1.39

\section{REFERENCIAS BIBLIOGRÁFICAS}

Antolín, M. N. (1998). Las estrategias de cooperación tecnológica con la universidad en la industria de las tecnologías de la información y las comunicaciones. Dirección y Organización, (19).

Medeiros, C., \& Trebat, N. (2017). Finance, trade, and income distribution in global value chains: implications for developing economies and Latin America. Instituto de Economia, UFRJ, Discussion Paper, 2, 2017.

Sutz, J. (2000). The university-industry-government relations in Latin America. Research policy, 29(2), 279-290.

Fuentes de financiamiento: Esta investigación fue financiada con fondos del autor.

Declaración de conflicto de intereses: El autor declara que no tiene ningún conflicto de interés.

Copyright (c) 2021 Roberto Guachi,

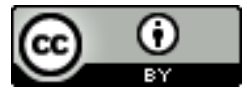

Este texto está protegido por una licencia CreativeCommons 4.0

Usted es libre para Compartir — copiar y redistribuir el material en cualquier medio o formato- y Adaptar el documento —remezclar, transformar y crear a partir del material - para cualquier propósito, incluso para fines comerciales, siempre que cumpla la condición de:

Atribución: Usted debe dar crédito a la obra original de manera adecuada, proporcionar un enlace a la licencia, e indicar si se han realizado cambios. Puede hacerlo en cualquier forma razonable, pero no de forma tal que sugiera que tiene el apoyo del licenciante o lo recibe por el uso que hace de la obra. 